\title{
Aetiological Profile and Antibiogram of Urinary Isolates Causing UTI in Patients Attending a Tertiary Care Hospital of Western Odisha
}

\author{
Shuvankar Mukherjee ${ }^{1}$, Suchitra Mishra², Shreekant Tiwari ${ }^{3}$ \\ 1Department of Microbiology, Hitech Medical College and Hospital, Rourkela, Odisha, India. ${ }^{2}$ Department of \\ Microbiology, Hitech Medical College and Hospital, Rourkela, Odisha, India, ${ }^{3}$ Department of Microbiology, Hitech \\ Medical College and Hospital, Rourkela, Odisha, India.
}

\section{ABSTRACT}

\section{BACKGROUND}

Although UTI is a female disease, males are also susceptible during the neonatal period and old age. Asymptomatic bacteriuria, cystitis and acute urethral syndrome are the most common clinical type. Etiological profile is variable in different geographical areas, but E. coli is the most common agent worldwide. Klebsiella, Proteus, Pseudomonas are important causes of hospital acquired UTI. Culture sensitivity of early morning mid-stream urine collected by clean catch technique is the gold standard method of diagnosis of UTI. Sensitivity to $3^{\text {rd }}$ generation cephalosporins and cotrimoxazole is variable in different areas but aminoglycoside, nitrofurantoin and carbapenem are almost sensitive worldwide. Resistance to nitrofurantoin and carbapenem has been reported in many areas of world. Before starting empirical therapy, physician should know the local etiological profile and antibiotic sensitivity pattern of uropathogens. We wanted to study the etiological profile and antibiotic sensitivity pattern of urinary isolates in a tertiary care hospital of Western Odisha.

\section{METHODS}

Early morning mid-stream urine samples of 730 clinically suspected UTI patients were collected by clean catch technique and sent to microbiology department. Cysteine lactose electrolyte deficient (CLED) agar media was seeded with urine with the help of $0.01 \mathrm{ml}(4 \mathrm{~mm})$ loop. After incubation for $24 \mathrm{hrs}$ at $37^{\circ} \mathrm{C}$ growth was observed and identified by Gram stain and biochemical tests. Antibiotic sensitivity was performed by disc diffusion method as per CLSI guidelines. Antibiotic sensitivity was performed for all Gram-negative bacteria, Enterococci and Staphylococcus.

\section{RESULTS}

Among 730 samples, 238 (33\%) showed significant bacteriuria and $63 \%$ of significant bacteriuria samples were from female. Middle age females (36-50 yrs.) were more affected (38\%) followed by old age ( $>50 \mathrm{yrs}$.) male (19\%) and old age ( $>50$ yrs.) female (18\%). E. coli was the most common bacteria (31\%) followed by Enterococci (18\%). Fluoroquinolones like nalidixic acid and norfloxacin showed high resistance rate $(31 \%, 42 \%$ in case of Gram-negative bacteria and $12 \%, 25 \%$ in case of Staphylococcus species respectively). Nitrofurantoin showed excellent sensitivity to both Gram-positive cocci and Gram-negative bacilli. (80\% for gramnegative bacilli and $87 \%$ for Staphylococcus species and 78\% for enterococci species). Aminoglycoside and carbapenem showed excellent sensitivity to Gramnegative bacteria ( $81 \%$ and $92 \%$ respectively). Third generation cephalosporins showed poor sensitivity ( $48 \%$ to $53 \%$ ).

\section{CONCLUSIONS}

Enterococci rather than Klebsiella species was the $2^{\text {nd }}$ most common uropathogen in our study. Aminoglycoside was still useful for UTI. Nitrofurantoin was the best option for empirical therapy.

\section{KEY WORDS}

UTI, Aetiology, Antibiogram, Bacteria, Sensitivity
Corresponding Author: Shuvankar Mukherjee, Staff Quarters, Room No. 28, Hitech Medical College, Rourkela, Odisha, India.

E-mail: shmu963@gmail.com

DOI: $10.14260 /$ jemds/2020/144

Financial or Other Competing Interests: None.

How to Cite This Article:

Mukherjee S, Mishra S, Tiwari S, . Aetiological profile and antibiogram of urinary isolates causing uti in patients attending a tertiary care hospital of Western Odisha. J. Evolution Med. Dent. Sci. 2020;9(09):662-667, DOI: 10.14260/jemds/2020/144

Submission 09-12-2019, Peer Review 04-02-2020,

Acceptance 11-02-2020,

Published 02-03-2020. 


\section{BACKGROUND}

Urinary tract infection is classified clinically as urethritis, asymptomatic bacteriuria, cystitis, acute urethral syndrome and pyelonephritis. ${ }^{1}$ Clinical symptoms of urethritis is dysuria and frequency. Asymptomatic bacteriuria means patients is symptomless but excreting bacteria more or equal to $10^{5} \mathrm{CFU} / \mathrm{ml}^{1}$ Most common type of infection is cystitis which is manifested as dysuria, frequency, urgency and tenderness over bladder area and sometimes bloody urine. As cystitis is a localised infection, fever and other signs of a systemic illness are absent. ${ }^{1}$ Acute urethral syndrome is manifested as dysuria, frequency and urgency in young sexually active woman who excrete bacteria fewer than $10^{5}$ $\mathrm{CFU} / \mathrm{ml}$ in urine. Almost $50 \%$ of all women who complain of burning micturition fall into this group. Pyelonephritis is a systemic infective condition involving kidney calices, pelvis and manifested by fever and flank pain. ${ }^{1}$ Global annual incidence of UTI is 150 million costing about 6 billion dollar per year. ${ }^{2}$ Approximately $10 \%$ of human will have a UTI at some times during their lives. UTI is also a common nosocomial infection. ${ }^{1}$ UTI is important complication of Diabetes, renal transplantation, renal disease, structural and neurological abnormality that interfere with urinary flow. Escherichia coli is the most frequent causative agent of community acquired UTI. Other bacteria frequently causing UTI are Klebsiella spp., Citrobacter spp., Enterobacter spp., Acinetobacter spp., Coagulase negative Staphylococcus, Staphylococcus aureus and Enterococci. Pseudomonas, Klebsiella and Enterobacter are responsible for complicated UTI. ${ }^{1}$ The hospital environment is the source of organisms involved in nosocomial UTI. Bacteria can invade and cause UTI via two routes- ascending and haematogenous pathway. ${ }^{1}$ In ascending pathway responsible bacteria first colonize the vaginal cavity and periurethral area and then enter into the bladder, multiply in the bladder and then pass up to ureters to the kidney. ${ }^{3}$ UTI may also occur by the haematogenous route in less than $5 \%$ of cases. ${ }^{4}$ the exact prevalence of UTI is dependent on age and sex. In the neonatal period, UTI are less than $2 \%$ in male and female. ${ }^{1}$ the incidence of UTI among males remains relatively low after neonatal period and until 60 years of age when BPH obstruct the urine flow, therefore UTI is more prevalent in female. Recurrence and persistence of infection is also common in female. Sexual activity and hormonal changes are two important causes of high incidence of UTI in female of young age group. Culture sensitivity is the gold standard method of laboratory diagnosis of UTI. Any colony count more or equal to $10^{5} \mathrm{CFU} / \mathrm{ml}$ is significant bacteriuria. (by KaaS concept). If the organism is Staphylococcus specie, or patient is pregnant/diabetic, or patient is already on antibiotic therapy low colony count is also significant. An early morning mid-stream urine collected by clean catch technique is the best sample for culture sensitivity provided that the sample is collected in sterile container and processed within 2 hrs. of collection. Physician of developing country like India usually prescribe empirical antibiotic therapy just after getting complain of burning micturition and positive RE/ME report. So local microbial profile and antibiotic sensitivity should be known to physician in every region. Keeping it in mind we have conducted research to find out etiological profile of urinary isolates of UTI and their sensitivity in patients attending a tertiary care hospital of Western Odisha.

\section{METHODS}

This is a cross-sectional study carried out in the Department of Microbiology of a tertiary care hospital of Western Odisha for a period of 3 months from Sep 2019 to Nov 2019. Urine samples from 730 patients (clinically suspected for UTI) both from IPD and OPD were collected. Patient who were already in antibiotic therapy were excluded from the study.

\section{Sample Collection}

Patient was explained and instructed to collect early morning mid-stream urine into a $20 \mathrm{ml}$ sterile container after proper cleaning of the genitalia with soap water. The samples were immediately transported to microbiology laboratory and processed within $2 \mathrm{hrs}$. of collection.

\section{Sample Processing}

Cysteine lactose electrolyte deficient (CLED) agar media was streaked ( $\mathrm{t}$ streaking method) with the help of a nichrome wire loop of $4 \mathrm{~mm}(0.01 \mathrm{ml})$.The plates were incubated at 37 ${ }^{0} \mathrm{C}$ in incubator for $24 \mathrm{hrs}$. Next day growth was observed and Gram stain of colony was performed to identify it as GPC or GNB colony. Catalase test and slide coagulase test were performed in any GPC colony for presumptive identification of Staphylococcus. Oxidase test was performed in NLF (nonlactose fermenting) colony to rule out Pseudomonas. Indole test, TSI test, Urease test and Citrate test were put in any GNB growth. Mannitol and tube coagulase were put for any GPC colony. Bile esculin test was put in GPC colony which showed diplococci in angle on gram stain. All biochemical tests were incubated in incubator at $37^{\circ} \mathrm{C}$ for $24 \mathrm{hrs}$. Motility was checked for any GNB by hanging drop preparation. Colony count of growth was determined by multiplying 100 to number of colony as $\mathrm{CFU} / \mathrm{ml}$. Any count more than $10^{5} \mathrm{CFU} /$ $\mathrm{ml}$ was considered significant. Inoculum of growth in peptone water was made and adjusted to $0.5 \mathrm{McF}$ arland as per CLSI (clinical and laboratory standard institute) guideline. ${ }^{5}$ Then the inoculum was seeded into Muller Hinton agar by lawn culture method with the help of sterile swab stick. Antibiotic discs were put into plate and incubated for 24 hrs. By Kirby Bauer disc diffusion method ${ }^{6}$ antibiotic sensitivity test was performed. All the media and antibiotics were purchased from HiMedia, Mumbai.

\section{Antibiotic Panel}

Antibiotic for GNB were Amikacin $(30 \mu)$, Cefoperazone (75 $\mu)$, Cefoperazone sulbactam $(75 / 30 \mu)$ Piperacillin tazobactam, $(100 / 10 \mu)$ Piperacillin $(100 \mu)$, Cotrimoxazole, Netilmicin $(30 \mu)$ Tigecycline, Amoxiclav $(20 / 10 \mu)$ Ciprofloxacin $(5 \mu)$, Nalidixic acid $(30 \mu)$, Norfloxacin $(10 \mu)$, Ceftriaxone $(30 \mu)$ Gentamycin $(10 \mu)$, Meropenem $(1 \mu)$, Imipenem $(10 \mu)$ Nitrofurantoin $(100 \mu)$ and special antibiotic for Pseudomonas were Ceftazidime $(30 \mu)$ Ceftazidime clavulanic acid $(30 / 10 \mu)$, Azithromycin $(15 \mu)$. Linezolid $(30 \mu)$, Nitrofurantoin $(100 \mu)$ Ciprofloxacin $(5 \mu)$ Cotrimoxazole, Gentamycin $(10 \mu)$ Erythromycin $(15 \mu)$, Clindamycin $(2 \mu)$, Tigecycline, Nalidixic acid $(30 \mu)$ and Norfloxacin $(10 \mu)$ were put for any catalase positive GPC 
growth (Staphylococcus). Ampicillin $(10 \mu)$, Ampicillin sulbactam $(10 / 10 \mu)$, Teicoplanin, Linezolid $(30 \mu)$, Nitrofurantoin $(100 \mu)$ Ciprofloxacin $(5 \mu)$, Cotrimoxazole and Gentamycin $(10 \mu)$ were put for any catalase negative GPC growth (enterococci).

\section{Quality Control}

E. coli ATCC 25922, Staphylococcus aureus ATCC 29213, Pseudomonas aeruginosa ATCC 27853, E. faecalis ATCC 29212 strains were used for quality control of biochemical test and antibiotic sensitivity test.

\section{Data Analysis}

Data analysis was done by SPSS software version 17 .

\section{RESULTS}

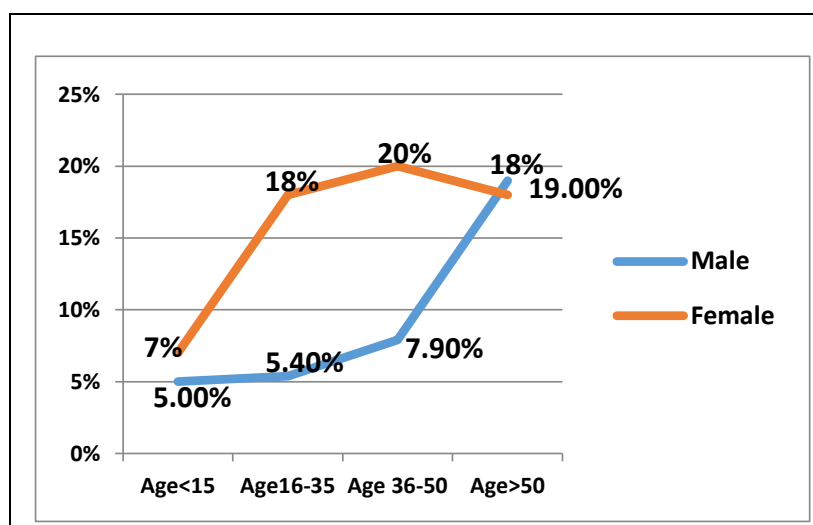

Figure 1. Age Wise Distribution of Significant Bacteriuria
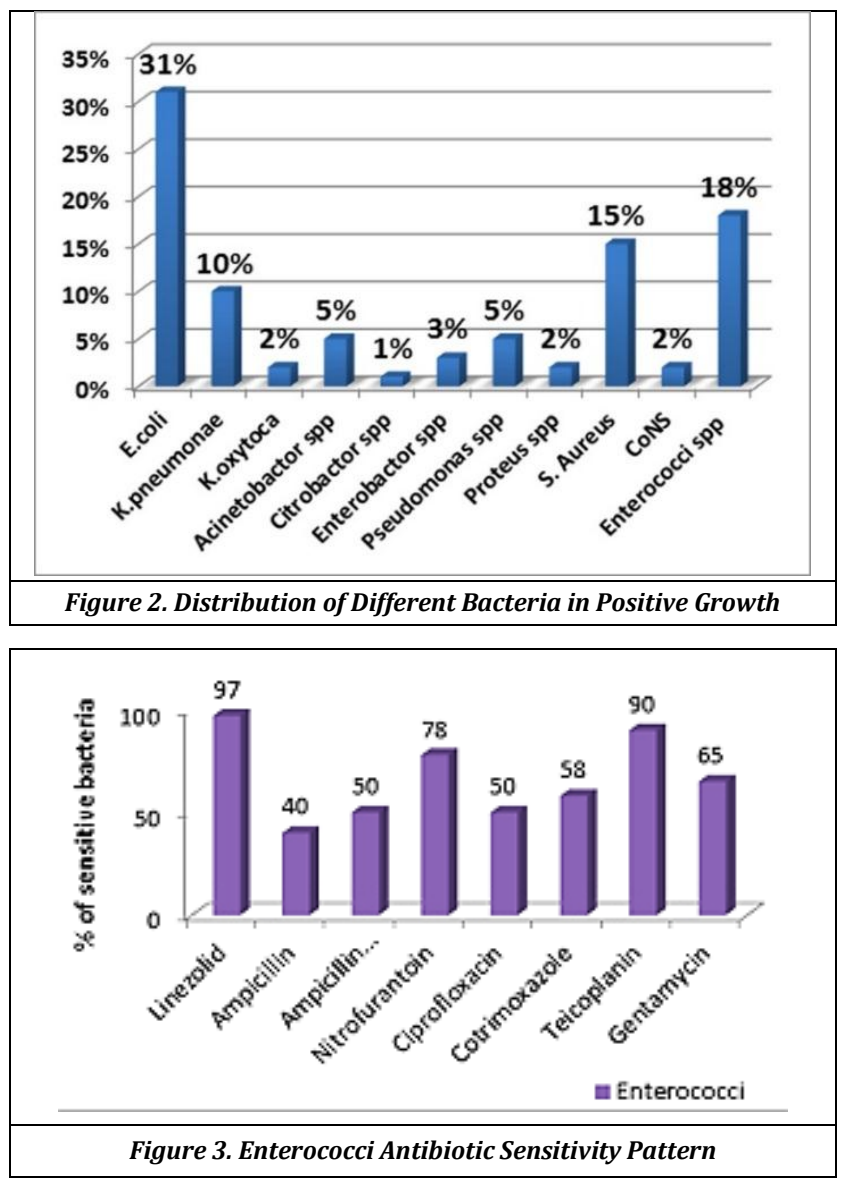

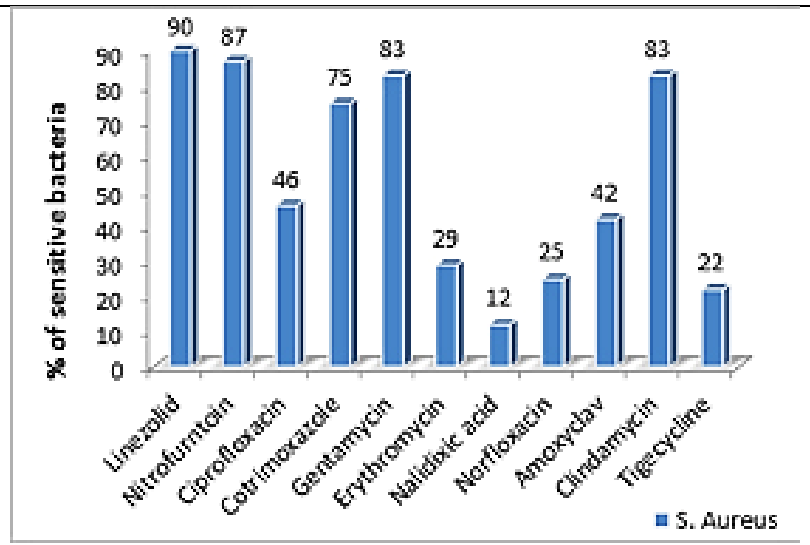

Figure 4. Staphylococcus aureus Antibiotic Sensitivity Pattern

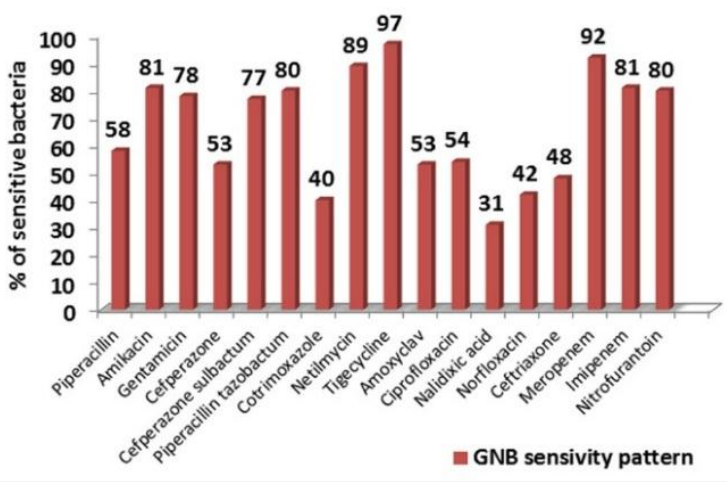

Figure 5. Gram Negative Bacteria (GNB) Antibiotic Sensitivity Pattern

\begin{tabular}{|c|c|c|c|c|c|c|c|c|}
\hline 䒿 & 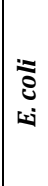 & 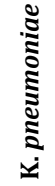 & 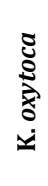 & 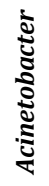 & 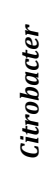 & 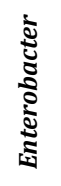 & 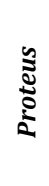 & 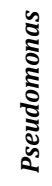 \\
\hline $\mathrm{Pi}$ & 44 & 79 & 43 & 80 & 67 & 89 & 80 & 60 \\
\hline $\mathrm{Ak}$ & 85 & 79 & 71 & 73 & 67 & 100 & 80 & 67 \\
\hline Gen & 78 & 82 & 71 & 73 & 67 & 89 & 80 & 67 \\
\hline CPZ & 42 & 73 & 0 & 60 & 67 & 67 & 80 & 94 \\
\hline CFS & 78 & 70 & 57 & 80 & 34 & 78 & 80 & 100 \\
\hline $\begin{array}{l}\text { PIT } \\
\end{array}$ & 82 & 79 & 71 & 100 & 34 & 89 & 80 & 67 \\
\hline COT & 63 & 76 & 57 & 80 & 34 & 67 & 60 & 94 \\
\hline NET & 92 & 76 & 86 & 87 & 100 & 100 & 80 & 100 \\
\hline TGC & 100 & 94 & 100 & 94 & 67 & 89 & 100 & 100 \\
\hline AMC & 45 & 64 & 0 & 80 & 67 & 67 & 20 & 87 \\
\hline CIP & \begin{tabular}{|l|}
46 \\
\end{tabular} & 76 & 0 & 73 & 34 & 67 & 60 & 77 \\
\hline NA & 20 & 45 & 0 & 47 & 34 & 44 & 40 & 80 \\
\hline $\mathrm{NX}$ & 32 & 48 & 0 & 73 & 34 & 56 & 40 & 87 \\
\hline CTR & \begin{tabular}{|l|}
36 \\
\end{tabular} & 67 & 0 & 73 & 34 & 56 & 60 & 94 \\
\hline MRP & \begin{tabular}{|l|}
95 \\
\end{tabular} & 82 & 100 & 94 & 67 & 89 & 100 & 94 \\
\hline IPM & \begin{tabular}{|l|}
79 \\
\end{tabular} & 82 & 100 & 94 & 34 & 89 & 60 & 53 \\
\hline NIT & \begin{tabular}{|l|}
93 \\
\end{tabular} & 74 & 100 & 67 & 100 & 67 & 60 & 60 \\
\hline GAT & NA & NA & NA & $\mathrm{NA}$ & NA & $\mathrm{NA}$ & NA & 67 \\
\hline CAZ & $\mathrm{NA}$ & NA & NA & NA & NA & NA & NA & 47 \\
\hline CAC & \begin{tabular}{|l|}
$\mathrm{NA}$ \\
\end{tabular} & NA & $\mathrm{NA}$ & NA & NA & NA & NA & 47 \\
\hline AT & NA & NA & NA & NA & NA & NA & NA & 60 \\
\hline \multicolumn{9}{|c|}{$\begin{array}{l}\text { Table 1. Percentage (\%) of Sensitive Strains of Different } \\
\text { Gram-Negative Bacteria to Different Antibiotics }\end{array}$} \\
\hline \multicolumn{9}{|c|}{$\begin{array}{l}\text { AK=Amikacin, Pi=Piperacillin, Gen=Gentamycin, CPZ=Cefoperazone CFS= } \\
\text { Cefoperazone sulbactam, PIT=Piperacillin tazobactam, COT=Cotrimoxazole } \\
\text { Net=Netilmicin, TGC= Tigecycline, AMC= Amoxiclav, CIP=Ciprofloxacin, } \\
\text { NA=Nalidixic acid. NX=Norfloxacin, CTR=ceftriaxone, MRP=Meropenem, } \\
\text { IPM=Imipenem, NIT=Nitrofurantoin, GAT=Gatifloxacin, CAZ=Ceftazidime, } \\
\text { CAC=Ceftazidime clavulanic acid AT= Azithromycin }\end{array}$} \\
\hline
\end{tabular}

Out of 730 sample $53 \% \quad(390 / 730)$ showed no growth,33\% (238/730) showed significant bacteriuria. 12\% (88/730) showed Insignificant bacteriuria and 2\% (14/730) showed growth of budding yeast cell (BYC). Among 238 
patients of significant bacteriuria $63 \%$ were female and $37 \%$ were male. Among male patients with significant bacteriuria $5 \%$ were in age group of less than $15,5.4 \%$ in age group of 16 $35,7.9 \%$ in age group of $36-50$ and $19 \%$ in age group of more than 50. Among female patients with significant bacteriuria $7 \%$ were in age group of less than $15,18 \%$ in age group of $16-$ $35,20 \%$ in age group of $36-50$ and $18 \%$ in age group of more than 50. (figure 1).

Among 326 positive growth $31 \%$ was E. coli,10\% was Klebsiella pneumoniae,2\% was Klebsiella oxytoca, 5\% was Acinetobactor spp.,1\% was Citrobactor spp., 3\% was Enterobactor, 5\% was Pseudomonas spp.,2\% was Proteus spp., $15 \%$ was $S$. aureus, $2 \%$ was CoNS, $18 \%$ was Enterococci. (figure2) Antibiotic sensitivity pattern of gram positive bacteria were showed in figure 3 (enterococci) and figure 4 (s.aureus) Antibiotic sensitivity pattern of Gram negative bacteria were showed in figure 5 . Table 1 showed antibiotic sensitivity pattern of individual Gram negative bacteria.

\section{DISCUSSION}

All women who have been colonised in the vaginal or periurethral area by uropathogen do not develop UTI. Complex interplay of host and microbial factors determines the outcome of the colonisation ${ }^{1}$. Acidic ph. osmolarity of urine, high concentration of toxic waste of body, organic acid concentration of urine is inhibitory to many bacteria. ${ }^{1}$ Constant flushing of urine, antibacterial substance released from uroepithelium, valve like mechanism in junction of ureter and bladder, TNF, IFN gamma, released due to stimulation by lipopolysaccharide, Tamm-Horsfall protein or uromucoid from uroepithelium that binds with type 1 fimbriae of $E$. coli are protective for host and prevent UTI development. ${ }^{1}$ However mechanical obstruction resulting from kidney stone, stricture impairment of valve action between ureter and bladder, hormonal changes during pregnancy all can impair host protective mechanism leading to UTI. Most cases of UTI are caused by only a few organisms although any uropathogen can cause UTI. For example, a limited number of serogroups of E. coli (UPEC) 7,8 that express type 1 fimbriae or type P fimbriae, invade urinary tract and cause UTI.7 Proteus and Klebsiella increase pH of urine and promote UTI. Some uropathogen strain produce more K antigen and inhibit phagocytosis. Staphylococcus saprophyticus (CoNS) has more attraction than S. aureus to uroepithelium and cause UTI in sexually active young women. According to Anderson' 'PODS' formed by intra cellular bacteria is responsible for persistent infection and repeated recurrence.

In our study out of 730 samples, 238 (33\%) showed significant bacteriuria which was higher than Afroza et al $(6.87 \%)^{10}$, Arshi et al $(30 \%),{ }^{11}$ Angamiet et al $(28.1 \%)^{12}$ but lower than Nzalie et al (58.8\%),13 Maheswary et al $(63.51 \%),{ }^{15}$ Prakash et al $(53.82 \%),{ }^{16}$ Taye et al $(36 \%),{ }^{16}$ khan et al (54.4\%), ${ }^{17}$ Manjunath et al $(42.37 \%)^{18}$ it was very similar to Dash et al $(34.5 \%)^{19}$ most probably due to similar environmental niche. BYC was positive in $2 \%$ growth and it was lower than Manjunath et al (4.5\%) ${ }^{18}$ and Venkatesh et al $(6 \%)^{20}$ among significant bacteriuria $63 \%$ were in female and $37 \%$ in male. Female were more susceptible to UTI and It was almost universal finding. It was showed in study done by Manjunath et al, ${ }^{18}$ Maheswary et al, ${ }^{14}$ Arshi et al,11 Afroza et al, ${ }^{10}$ Angamiet et al,12 Prakash et al ${ }^{15}$ Dash et al, ${ }^{19}$ Taye et al, ${ }^{17}$ Khan et $\mathrm{al}^{17}$, Nzalie et $\mathrm{al}^{13}$ and Jubina et $\mathrm{al}^{21}$ Oladeinde et $\mathrm{al}^{22}$ Kashef et al. ${ }^{23}$ Females were more affected due to proximity of urethral meatus to the anus, shorter urethra, less acidic $\mathrm{Ph}$ of the vaginal fluid 24,25 . Males outnumbered female only in elderly $(>50)$ age group (19\% vs $18 \%)$ in our study which was similar to Khan et al (38.1\% vs $10.8 \%),{ }^{17}$ Shankel et al $(23 \%$ vs $19 \%),{ }^{26}$ Prakash et al(43\% vs $\left.22.4 \%\right)^{15}$ and Sood et al $(20.7 \%$ vs $17.34 \%) .{ }^{27}$ Elderly male were more susceptible due to neurogenic bladder and $\mathrm{BPH}($ Benign prostatic hyperplasia) than younger male. ${ }^{19}$ In our study Most prevalent bacteria was E. coli (31\%) followed by Enterococci (18\%),S aureus (15\%) Klebsiella pneumoniae (10\%). The least common bacteria was Citrobacter (1\%).This finding was very similar with Dash et al ${ }^{19}(68.8 \%$ E. coli followed by $9.7 \%$ Enterococci), Manjunath et al $(60.7 \%$ E. coli followed by $12.1 \%$ Enterococci species) ${ }^{18}$ and Arshi et al(56.7\% E. coli followed by $13.1 \%$ Enterococci species) ${ }^{11}$ but not consistent with the most of the studies worldwide. Klebsiella was the $2^{\text {nd }}$ most common bacteria in Nzalie et al $^{13}$ Angamiet et al, ${ }^{12}$ Prakash et al,15 Taye et al,16 Jubina et $\mathrm{al}^{21}$, khan et ${ }^{15},{ }^{17}$ Mahajan et al. ${ }^{28}$ Akochere ET al $^{29}$ showed that Klebsiella was the least prevalent $(1.2 \%)$ bacteria in UTI. Ehinmidu ET al ${ }^{30}$ showed that Pseudomonas was the most common (32\%) bacteria in UTI.

In antibiotic sensitivity test of GNB overall highest sensitivity was showed by Tigecycline $(97 \%)$ followed by Meropenem (92\%), Netilmicin (89\%), Imipenem (81\%), Amikacin (81\%), Nitrofurantoin (80\%) Piperacillin Tazobactam (80\%), Gentamycin (78\%) Low sensitivity was showed by Nalidixic Acid (31\%), Cotrimoxazole (40\%), Norfloxacin (42\%), Ceftriaxone (48\%), Cefoperazone (53\%). High sensitivity to carbapenem, aminoglycoside, nitrofurantoin and low sensitivity to $3^{\text {rd }}$ generation cephalosporin, fluoroquinolones and cotrimoxazole were showed by Maheswary et al, ${ }^{14}$ Afroza et al, ${ }^{10}$ Mahajan et al, ${ }^{28}$ Prakash et $\mathrm{al}^{15}$ Dash et $\mathrm{al}^{19}$ Jubina et $\mathrm{al}^{21}$ khan et al,17 Angamiet et al. ${ }^{12}$ In case of Staphylococcus high sensitivity was seen in Linezolid (90\%) Nitrofurantoin (87\%) Gentamycin (83\%), Clindamycin (83\%), Cotrimoxazole (73\%). Low sensitivity was seen in nalidixic acid, norfloxacin, erythromycin, tigecycline and ciprofloxacin. Enterococci also showed high sensitivity to linezolid, teicoplanin and nitrofurantoin and aminoglycoside but lower sensitivity to ampicillin, ampicillin sulbactam, cotrimoxazole and fluoroquinolones and this finding was similar to Prakash et al,15 Dash et al,19 Khan et al $^{17}$ and Mahajan et al. ${ }^{28}$ Cotrimoxazole showed sensitivity only to Staphylococcus but showed poor sensitivity to Enterococcus and gram negative bacteria so it is not appropriate to use it as antibiotic of choice in empirical therapy. Fluroquinolones like nalidixic acid, norfloxacin, ciprofloxacin is of no use today for UTI as more than $50 \%$ of bacteria were resistant to it and it was a universal finding all over the world. $3^{\text {rd }}$ generation cephalosporin was used so much not only for UTI but also for another infection that it was now resistant to almost all uropathogen. Aminoglycoside was still fighting against all uropathogen, most probably due to less use in community acquired infection. As it was an injectable antibiotic, it could not be selected as empirical agent. So the remaining oral 
option was one and only Nitrofurantoin. In spite of high sensitivity, Carbapenem should not be used in uncomplicated UTI otherwise within decade it will be useless like fluoroquinolones.

\section{CONCLUSIONS}

Enterococci rather than Klebsiella spp. was the $2^{\text {nd }}$ most common uropathogen in our study. Cotrimoxazole can be used if only Staphylococcal infection is suspected or confirmed but not for Enterococci or Gram negative bacteria. $3^{\text {rd }}$ generation cephalosporin and fluoroquinolones should be avoided in UTI due to high resistance rate. Aminoglycoside was still useful for UTI in our study. Nitrofurantoin was the best option for empirical antibiotic therapy.

\section{REFERENCES}

[1] Forbes BA, Sahm DF, Weissfeld AS. Study guide for Bailey \& Scott's Diagnostic microbiology. $12^{\text {th }}$ edn. USA: Mosby 2007.

[2] Kattel HP, Mishra SK, Acharya J, et al. Antibiotic sensitivity profile of different uropathogens in a tertiary care center in Nepal. Journal of Nepal Association of Medical Laboratory Science 2012;11(1):19-33.

[3] Foxman B, Brown P. Epidemiology of urinary tract infections: transmission and risk factors, incidence and costs. Infectious Disease Clinics of North America 2003;17(2):227-41.

[4] Mustafa M, Tamin J, Balingi J. Urinary tract infections in a Sabah general hospital. IOSR J Pharm \& Biol Sci (IOSRJPBS) 2012;1(6):44-8.

[5] Bauer A, Kirby WM, Sherris JC, et al. Antibiotic susceptibility testing by a standardized single disk method. American Journal of Clinical Pathology 1966;45(4):493-6.

[6] Clinical and Laboratory Standards Institute. Performance standards for antimicrobial disk susceptibility tests. Wayne, Pa: Clinical and Laboratory Standards Institute: M100-S16, 2006.

[7] Kucheria R, Dasgupta P, Sacks SH, et al. Urinary tract infections: new insights into a common problem. Postgraduate Medical Journal 2005;81(952):83-6.

[8] Stamm WE, Hooton TM, Johnson JR, et al. Urinary tract infections: from pathogenesis to treatment. The Journal of Infectious Diseases 1989;159(3):400-6.

[9] Anderson GG, Martin SM, Hultgren SJ. Host subversion by formation of intracellular bacterial communities in the urinary tract. Microbes and Infection 2004;6(12):1094101.

[10] Begum A, Anjum MF, Huq SS, et al. Bacteriologic profile and drug sensitivity pattern of urinary tract infection in children with renal diseases in a tertiary care hospital, Dhaka, Bangladesh. J Emerg Intern Med 2017;1(1):11.

[11] Arshi S, Suhail M, Khurshid S, et al. Microbiological profile of urinary tract infections and it antibiotic susceptibility profile in a tertiary care hospital. International Journal of Current Advanced Research 2017;6(7):4975-7.
[12] Angami S, Jamir N, Sarma PC, et al. Urinary tract infection, its causative microorganism and antibiotic susceptibility in Nagaland. Archives of Medicine and Health Sciences 2015;3(1):40-3.

[13] Nzalie R, Gonsu H, Koulla-Shiro S. Bacterial etiology and antibiotic resistance profile of community-acquired urinary tract infections in a Cameroonian city. International Journal of Microbiology 2016:1-6.

[14] Maheswary D, Saikumar C. Profile of urinary tract infections and resistance patterns in a tertiary care hospital in India. Int J Curr Microbiol App Sci 2018;7 (3):506-12.

[15] Prakash D, Saxena RS. Distribution and antimicrobial susceptibility pattern of bacterial pathogens causing urinary tract infection in urban community of Meerut City, India. Article ID 749629, ISRN Microbiology 2013; 2013:1-13.

[16] Taye S, Getachew M, Desalegn Z, et al. Bacterial profile, antibiotic susceptibility pattern and associated factors among pregnant women with Urinary Tract Infection in Goba and Sinana Woredas, Bale Zone, Southeast Ethiopia. BMC Research Notes 2018;11 (1):799.

[17] Khan R, Saif Q, Fatima K, et al. Clinical and bacteriological profile of Uti patients attending a north Indian tertiary care center. Journal of Integrative Nephrology and Andrology 2015;2(1):29-34.

[18] Manjunath GN, Prakash R, Annam V, et al. Changing trends in the spectrum of antimicrobial drug resistance pattern of uropathogens isolated from hospitals and community patients with urinary tract infections in Tumkur and Bangalore. Int $\mathrm{J}$ Biol Med Res 2011;2(2):504-7.

[19] Dash M, Padhi S, Mohanty I, et al. Antimicrobial resistance in pathogens causing urinary tract infections in a rural community of Odisha, India. J Fam Community Med 2013;20(1):20-6.

[20] Venkatesh RK, Prabhu MM, Nandakumar K, et al. Urinary tract infection treatment pattern of elderly patients in a tertiary hospital setup in south India: a prospective study. Journal of Young Pharmacists 2016;8(2):108-13.

[21] Bency JAT, Priyanka R, Jose P. A study on the bacteriological profile of urinary tract infection in adults and their antibiotic sensitivity pattern in a tertiary care hospital in central Kerala, India. Int J Res Med Sci 2017;5(2):666-9.

[22] Oladeinde $\mathrm{BH}$, Omoregie R, Olley M, et al. Urinary tract infection in a rural community of Nigeria. North American Journal of Medical Sciences 2011;3(2):75-7.

[23] Kashef N, Djavid GE, Shahbazi S. Antimicrobial susceptibility patterns of community-acquired uropathogens in Tehran, Iran. The Journal of Infection in Developing Countries 2010;4(4):202-6.

[24] Ochei J, Kolhatkar A. Diagnosis of infection by specific anatomic sites/antimicrobial susceptibility tests. In: Medical Laboratory Science Theory and Practice Reprint. $6^{\text {th }}$ edn. New Delhi, India: McGraw-Hill Publication 2007;615-43, 788-98.

[25] Aiyegoro OA, Igbinosa 00, Ogunmwonyi IN, et aI. Incidence of urinary tract infections (UTI) among children and adolescents in Ile-Ife, Nigeria. African Journal of Microbiology Research 2007;1(2):13-9. 
[26] Shankel S. Urinary Tract Infections Genitourinary Disorders. The Merck Manuals Online Medical Library 2007.

[27] Sood S, Gupta R. Antibiotic resistance pattern of community acquired uropathogens at a tertiary care hospital in Jaipur, Rajasthan. Indian of Community Medicine: Official Publication of Indian Association of Preventive \& Social Medicine 2012;37(1):39-44.

[28] Mahajan DD, Bulle AD. Microbiological profile and antibiogram of bacterial isolates causing urinary tract infection in tertiary care hospital. IOSR Journal of Dental and Medical Sciences 2016;15(9):145-9.

[29] Akoachere JFTK, Yvonne S, Akum NH, et al. Etiologic profile and antimicrobial susceptibility of communityacquired urinary tract infection in two Cameroonian towns. BMC Research Notes 2012;5(1):219.

[30] Ehinmidu J0, Bolaji RO, Adegboye EE. Isolation and antibiotic susceptibility profile of Neisseria gonorrhoeae isolated from urine samples in Zara, Northern Nigeria. Journal of Phytomedicine and Therapeutics 2004;9(1):20-4. 